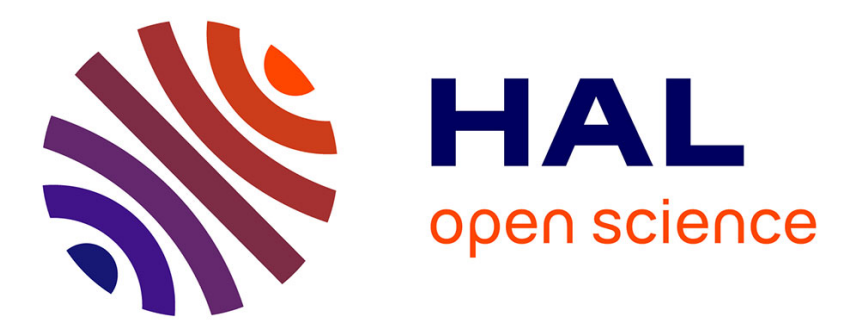

\title{
Sustainable food education: what food preparation competences are needed to support vegetable consumption?
}

\author{
Caroline Huyard
}

\section{- To cite this version:}

Caroline Huyard. Sustainable food education: what food preparation competences are needed to support vegetable consumption?. Environmental Education Research, 2020, Environmental Education Research, 26 (8), pp.1164-1176. 10.1080/13504622.2020.1779187 . hal-03095252

HAL Id: hal-03095252

https://hal.univ-lille.fr/hal-03095252

Submitted on 4 Jan 2021

HAL is a multi-disciplinary open access archive for the deposit and dissemination of scientific research documents, whether they are published or not. The documents may come from teaching and research institutions in France or abroad, or from public or private research centers.
L'archive ouverte pluridisciplinaire HAL, est destinée au dépôt et à la diffusion de documents scientifiques de niveau recherche, publiés ou non, émanant des établissements d'enseignement et de recherche français ou étrangers, des laboratoires publics ou privés. 
Sustainable food education: What food preparation competences are needed to support vegetable consumption?

\section{Funding details}

This work was supported by the regional authority Région Hauts de France.

\section{Disclosure statement}

No potential conflict of interest was reported by the authors.

\section{Data availability statement}

The data supporting the results will be made available upon request to the authors. 


\title{
Sustainable food education: What food preparation competences are needed to support vegetable consumption?
}

\begin{abstract}
Contributing to more sustainable diets is a major challenge for contemporary environmental education. It implies an increase in the share of plant-based foods and of home-cooked meals. Awareness of this is widespread but taking concrete action is not easy. What competences does it call for? To identify them, we proposed an 8-month training course to groups of young adults in France. Their consumption of vegetables and the competences they mobilized were collected at the end of the training and 8 months later. The competences used by the participants with the lowest consumption of vegetables included controlling their food budget, collecting information about processed foods and planning what they would like to eat. The competences used by the participants with the highest consumption included planning meal preparation, being flexible, choosing quality products and mastering the preparation of fresh vegetables. These results are of interest for designing education programmes for sustainable diets. (149 words)
\end{abstract}

Keywords: Food Preparation Skills, Cooking Skills, Food Skills, Culinary Skills, Food Competences, Food Sustainability, Sustainable Diet, Vegetable Consumption

\section{Introduction}

Contemporary food consumption patterns are a major environmental burden regarding greenhouse gas emissions, soil acidification, or eutrophication (Poore and Nemecek, 2018). They need to change deeply in a near future. Scholars agree that education is key to shift contemporary food consumption patterns towards sustainability (Sumner, 2016). Recent research highlighted that effective climate change education strategies should focus on personally relevant and meaningful information and use active and engaging teaching methods (Monroe et al., 2019), (Stibbe, 2009). This translates into the field of food practices where embodied forms of knowledge about healthy, ethical and resourceefficient food consumption should be prioritised and supported by a systems thinking approach and focused on home-made meal practice (Gisslevik, 2018). These results are essential to devise effective education strategies for sustainable food practices.

In terms of learning outcomes, scholars agree that to reduce the environmental impact of food consumption, diets should consist of sufficient but not excessive quantities, be varied and seasonal, 
and contain fewer energy-dense processed foods, less animal protein, less fat, less sugar, and less salt (Garnett, 2014), be more plant-based (Notarnicola et al., 2017), and more home-cooked (Schmidt Rivera et al., 2014). Eating more vegetables is an important means to meet these goals because (1) they contribute to a feeling of satiety and thus to reducing the amount of food we eat; (2) they are an important component of a diet's variety and seasonality, and (3) they can complement meals in a way that contributes to reducing the consumption of animal protein (by adding quantity, taste, and variety). Understanding what cooking competences are needed to improve vegetable consumption could therefore contribute to a much-needed behaviour change. There has been less research on this issue so far, for at least three reasons.

Defining cooking skills or cooking competences is not straightforward (Wolfson et al., 2017). Indeed, in spite of the alleged decline of cooking skills in developed countries over the past decades and evidence that most people do not meet international dietary recommendations (Expert Consultation on Diet, Nutrition, and the Prevention of Chronic Diseases et al., 2003), qualitative studies and self-reported data support the view that most respondents do have some cooking skills, for instance in Australia where 75\% of the respondents in a survey said they "cooked from scratch" (Worsley et al., 2015) or in Spain where 90\% of the respondents in a survey said they had cooking skills (García-González et al., 2018). Several hypotheses can be suggested: the respondents may overestimate their skills; the way food experts and respondents define cooking skills and food literacy may diverge (Stead et al., 2004) (Takeda et al., 2017); or some cooking skills may have more impact than others on the quality of a diet, and these key skills may be the precise few that the respondents do not have.

Measuring cooking skills produces some surprising results when studies aim at matching skills with the respondents' diet. Several measuring tools have been developed. They have been devised on the basis of contributions from a range of food experts and disciplines and with the purpose of assessing the impact of interventions aiming at improving cooking skills (Lahne et al., 2017) (Fordyce-Voorham, 2011) (Barton et al., 2011) (Lavelle et al., 2017). But when these tools are used to predict the quality of the respondents' diet, cooking skills appear not to be such a good predictor for healthy food choices (McGowan et al., 2016). Similarly, some studies reported no significant association between cooking skills and healthy eating index (Fernandez et al., 2019). It can be hypothesised that key cooking skills with a strong impact on diet may be relevant here as well, and that these cooking skills have not been fully incorporated in the measuring tools and in the cooking skills interventions.

Two other features of cooking skills tend to support this hypothesis. First, the complexity of the 
tasks to be performed and of the skills required by home cooking is generally underestimated (Short, 2003a), in particular regarding planning and organisation. Second, the definition of cooking skills for the purpose of a study is often performed by food experts, i.e. food professionals, although the home-cooking practices of home food preparers may be very different from those of professionals (Dinkins, 1997). This does not mean that home food preparers are not skilled; it is more probable that the skills they need are different from the skills needed by food professionals. This is why it appears fundamental to pay more attention to the skills that are actually used by home food preparers on a daily basis and to look at how these skills may impact diet.

Many definitions of cooking skills have been suggested (Jomori et al., 2018). For the purpose of the study, we will adopt a person-centred approach, which "focuses on the 'capabilities and practices of the cook' rather than the 'requirements of the cooking-task', as a task-centred approach might" (Short, 2003b). This leads to a very simple definition, based on a view of competences that is suited to many of the contexts where they are relevant (such as education or work): a competence is an action that a person performs in a reliable manner for a specific purpose (Le Boterf, 1994). We will address “food preparation competences” rather than "cooking competences” to avoid any ambiguity: cooking may be viewed as narrower, excluding organisation for instance, and may also be confused with food heating techniques. Similarly, we chose to consider competences rather than skills in order to clearly include tasks that are not so technical, such as organisational tasks. The purpose of this approach is to explore what food preparation competences are actually used, so as to determine how they may impact the diet.

We focused on vegetable preparation and consumption. Specifically, our goal was to determine which food preparation competences contribute to a diet that includes at least one portion of vegetables per day, and which food preparation competences are on the contrary likely to contribute to a diet that is poor in vegetables, even if they may be useful in other respects. As described in the Introduction, vegetable consumption is a cornerstone of sustainable diets and food preparation competences that support vegetable consumption are key to implement and sustain such diets.

\section{Materials and Methods}

The qualitative data were collected from a food training with young adults (students or recent graduates seeking employment). Young adults were chosen as the target population because there is evidence that young adults' diet, and in particular students' diet, is generally too poor in fruit and 
vegetables with respect to nutritional recommendations (Larson et al., 2012).

The study however did not consist of measuring the impact of the training, but it made use of it to access data on the participants' food preparation competences and on their diet. It draws on the notion of "test" as developed by the sociologists Luc Boltanski and Laurent Thévenot (Boltanski and Thévenot, 2006). A test can be viewed as a critical moment that confronts people with a disruption of their usual course of action. This disruption leads to reactions that are different from one person to another and that can be described and accounted for. According to Boltanski and Thévenot, people are able to provide "justifications" for these reactions. This is particularly important regarding habits or routines, because it can be difficult to reflect on this type of action when they are performed in the usual way. On the contrary, after a test, it makes sense to ask the participants what happened exactly, how they reacted, and why they reacted this way, because they can now think in a meaningful way about the investigated routines or habits. Interviewing the participants during the training and several months later was thus an opportunity to collect rich and robust qualitative data on their concrete practices.

The training was offered to students and recent graduates from the Lille region and the Calais region (in the north of France). It was designed to provide the participants with the means to improve the quality of their diet in a number of ways (more fruit and vegetables, more variety, more homecooked meals, a more balanced diet, a more sustainable diet, etc.) that they could prioritise according to their own needs. Upon enrolment, the participants were informed that the training would be used for a research project. The project and the data that would be collected were described to them, they were given the opportunity to ask questions, and then they signed a consent form.

Data on changes in food consumption and food preparation habits were collected by telephone interviews with the participants twice: firstly after five to seven months of training, and secondly eight to ten months after the end of the training. These in-depth qualitative interviews focused on (1) how participants fed themselves and prepared food (including purchasing and organisationrelated topics) before, during and after the training; (2) the resources they used for this purpose (kitchen utensils and appliances, cookbooks, internet sites, etc.); and (3) the specific changes they might have noticed during the training and the months that followed regarding the way they fed themselves and prepared food. Seven participants (out of ten) from the first class and four participants (out of six) from the second class took part in both rounds of interviews.

The interviews were recorded, transcribed and analysed so as to identify all the competences that the participants said they had used. The analysis was restricted to the competences that are relevant to preparing the main part of a meal and excluded the competences that relate to the preparation of desserts, bakers' confectionery and bread. A first list of food preparation competences had been 
established during the design of the training, with the purpose of defining which competences would be taught. This list was extended to include the competences described by the participants during the interviews. Both lists were then merged and structured in a unified manner using the structure and the items provided by Lavelle et al. (Lavelle et al., 2017), in order to draw on the important work that had already been done. Its structure was made more coherent, with the cooking techniques section dedicated to heating techniques only and the preparation techniques dedicated to product preparation only. Some competences from this list were rephrased to better take into account the complexity of the practices described in the interviews (and in particular to clearly differentiate two competences that are close but nevertheless distinct); some competences were added to the list; and some competences were removed, in order for all the competences to describe a single practice without any mention of an additional intention or related practice. The list that resulted from this process is presented in Table 1. Once this final list was established, the interviews were analysed a second time, with the aim of listing the competences that each individual participant had mentioned as being his/her regular practice.

Insert Table 1 here

For each of the participants who took part in two interviews, we determined what was his or her use of each competence at the beginning of the training, after 5-7 months of training and 8-10 months after the end of the training. The consumption of vegetables by the participants was estimated at these two moments in order to be associated with the food preparation competences they frequently used. For this purpose, concrete questions were asked about the meals the participants had prepared and eaten recently, how they purchased food, how they stored food, and how they prepared food, as well as the amount of vegetables they consumed for each period of time considered by comparison with the amount they consumed when they had the basket subscription.

The consumption of vegetables 8-10 months after the end of the training was addressed as the explained variable, and the competences used during the same period of time were addressed as the explanatory variable. The analysis focused on identifying (1) the competences that were used only by the participants with the highest level of vegetable consumption; (2) the competences that were used by these participants and by the participants who had an intermediate vegetable consumption, but not by the participants who had the lowest level of vegetable consumption; (3) the competences that were used only by the participants with the lowest vegetable consumption; and (4) the competences that were used by these participants and the participants who had an intermediate vegetable consumption, but not by the participants who had the highest level of 
vegetable consumption. When the participants explained that they had gone through different stages of consumption and different practices (because of professional training, a relocation, etc.), the period of time considered for the analysis was only the one they described the more precisely and accurately, in order to ensure that the data were homogeneous and of better quality.

\section{Results}

Of the 16 young adults who participated in the project, 11 could be interviewed twice. Of these 11 participants, seven were male and four female; three had completed the training while they were undergraduate students, six while they were postgraduate students and two while they were looking for a job; five participants lived alone and six lived with roommates or partners; and five lived in a student's room and six in an apartment. Eight to ten months after the end of the training, three participants reported a high consumption of vegetables, four reported an intermediate consumption and four reported a low consumption. In each of these three categories, there were participants living in a poorly equipped room and participants living alone. These characteristics can thus not be considered as hidden variables to explain the participants' competences and vegetable consumption.

Table 2 presents the competences, numbered according to Table 1, that the participants reported using frequently (grey boxes) or infrequently (boxes with I) 8-10 months after the end of the training, as well as their level of vegetable consumption. We have distinguished the competences that were used frequently (i.e. several times a month) and those that were not or were infrequently used (i.e. once a month or less). Distinguishing competences on the basis of their frequency of use is important for a study addressing the impact of food preparation competences on a diet. Indeed, a competence that is infrequently used will not have much impact. We have thus focused on the frequently used competences, and pointed out the infrequently used competences for the record.

Three levels of vegetable consumption were identified: the lowest level is that of the participants who said they did not consume vegetables at all or consumed them only very infrequently (less than once a week, buying fresh vegetables on a monthly basis on average); the intermediate level is that of the participants who said they consumed vegetables regularly but not very frequently (several times a week, but not every day, buying fresh vegetables once a fortnight on average); the highest level is that of the participants who described vegetables as a permanent component of their meals and said they consumed fresh vegetables very often (every day, buying or getting fresh vegetables once a week or more on average).

Insert Table 2 here 
The competences that are used only by the participants with the lowest consumption of vegetables are the following:

\section{Steam food (note: this cooking technique is one of the fastest for vegetables)}

43. Read the best-before date on food

47. Read the nutrition information on food labels

The competences that are used by the participants with the lowest consumption of vegetables and by the participants with an intermediate consumption but not by the participants with a high consumption are the following:

25. Define the meals you would like to eat first, and then go shopping with the corresponding grocery list

29. Prioritise price when choosing between two products

31. Know what budget you have to spend on food

32. Buy meat cuts that are easy to cook (best cuts such as beefsteak or processed meats such as sausages or nuggets)

In light of the contextualising elements provided by the interviews, these seven competences can be grouped into three subsets that provide an understanding of their underlying logic.

The first subset includes the competences 29 and 31 and refers to the participants with these competences giving priority to an economic criterion when buying food. The data provided by the interviews make it possible to say that this priority does not result from a tighter budget for these participants. On the contrary, some of those with the lowest vegetable consumption are also among the most privileged participants in this regard. This priority seems to stem from an approach to food that favours cheaper products over quality products (unlike the participants whose vegetable consumption is high, as we will see later on). The second subset of competences includes the competences 43 and 47 and refers to these participants buying processed products, which are those with a best-before date (43) and nutritional information (47). The third subset refers to these participants' particular expectations regarding the composition of a meal: it must be planned well in advance, regardless of the actual food production and supply (25), and it is centred on a meat component that is easy to prepare (32), whereby vegetables are a side dish that has to cook quickly (3).

\section{Competences That Have a Positive Impact on the Consumption of Vegetables}


The competences that are used only by the participants with the highest consumption of vegetables are the following:

15. Make sauces and gravy from scratch (no ready-made jars, pastes or granules)

18. Plan meal preparation ahead (e.g. for the day/week ahead)

22. Adapt the quantity of each ingredient to obtain a specific number of servings when cooking

40. Plan the different tasks and steps so as to optimise preparation duration when cooking

46. Store foods so as to best preserve them

The competences that are used by the participants with the highest consumption of vegetables and by the participants with an intermediate consumption but not by the participants with the lowest consumption are the following:

6. Roast or bake food in the oven, for example raw meat/chicken, vegetables, pies, gratins, etc.

11. Prepare fresh vegetables (including potatoes, e.g. peel when needed, chop, slice, grate, etc.)

16. Use herbs and spices to flavour dishes

17. Choose the appropriate mode of food preparation and cooking to make the most of available ingredients

21. Follow generic steps for preparing a type of dish when cooking (e.g. preparing a curry or a pie based on available ingredients and generic preparation and cooking techniques for this type of dish)

23. Buy vegetables and fruit from suppliers other than supermarkets (e.g. market, subscription, domestic production)

26. Buy fresh seasonal vegetables first, and then define the meals you will prepare based on these purchases

28. Plan how much food to buy

30. Prioritise quality when choosing between two products

35. Avoid buying meat

38. Cook more or double quantities, which can be used for another meal

39. Improvise if needed so as to use the items available in your fridge or cupboard

42. Keep basic items in your cupboard or fridge for putting meals together

In light of the contextualising elements provided by the interviews, these 18 competences can be grouped into four subsets that provide an understanding of their underlying logic.

A first subset relates to food preparation planning (planning purchases, quantities, meal preparation and tasks). The competences in this subset are the following: 
18. Plan meals ahead (e.g. for the day/week ahead)

22. Adapt the quantity of each ingredient to obtain a specific number of servings when cooking

28. Plan how much food to buy

38. Cook more or double quantities, which can be used for another meal

40. Plan the different tasks and steps so as to optimise preparation duration when cooking

46. Store foods so as to best preserve them

6. Roast or bake food in the oven, for example raw meat/chicken, vegetables, pies, gratins, etc. (note: this cooking technique makes it possible to cook large amounts at once)

These competences could play an important role regarding time management. They probably help the participants to schedule the relatively time-consuming preparation of plant-based dishes (18, 40) while keeping the duration of this preparation under control (in particular thanks to batch cooking and adequate storage: 22, 38, 6 and 46).

A second subset covers flexibility in meal preparation (i.e. an ability to adapt according to the available ingredients and to use generic steps for preparing a dish so as to be able to include some variations in terms of ingredients or quantities). The competences in this subset are the following:

21. Follow generic steps for preparing a type of dish when cooking (e.g. preparing a curry or a pie based on available ingredients and generic preparation and cooking techniques for this type of dish)

26. Buy fresh seasonal vegetables first, and then define the meals you will prepare based on these purchases

39. Improvise if needed so as to use the items available in your fridge or cupboard

42. Keep basic items in your cupboard or fridge for putting meals together

Thanks to such competences, meal preparation can rest on a handful of preparation outlines, where recipes are specific cases of these outlines. On the basis of the contextualising elements provided by the interviews, it can be hypothesised that this ability to take a general approach to the preparation instead of a particular one has the advantage of reducing the cognitive load and the organisational constraints that go with following recipes for everyday cooking. There is no more need to have specific ingredients at hand $(39,42)$ and no more need to spend time searching for new recipes and practising to master or correct them (21). The need for variety is met by the changes brought about by seasonality itself (26).

A third subset relates to a concern for the quality of the products. The competences in this subset are the following:

17. Choose the appropriate mode of food preparation and cooking to make the most of available 
ingredients

23. Buy vegetables and fruit from suppliers other than supermarkets (e.g. market, subscription, domestic production)

26. Buy fresh seasonal vegetables first, and then define the meals you will prepare based on these purchases

30. Prioritise quality when choosing between two products

The number of competences relating to quality is rather high. On the basis of the contextualising elements provided by the rest of the interviews, it can be hypothesised that the quality of the products $(23,26,30)$, and in particular the additional taste of fresh products $(23,26)$, makes eating a pleasant experience and, at the same time, reinforces the willingness to carry on home cooking with vegetables.

A last subset covers the specific demands of fresh vegetable consumption. The competences in this subset are the following:

11. Prepare fresh vegetables (including potatoes, e.g. peel when needed, chop, slice, grate, etc.)

15. Make sauces and gravy from scratch (no ready-made jars, pastes or granules)

16. Use herbs and spices to flavour dishes

35. Avoid buying meat

A high or intermediate consumption of vegetables seems to involve the consumption of a fair amount of fresh vegetables (11) and not just the consumption of frozen or canned vegetables. It also seems to involve a decrease in meat consumption (35) and a reshaping of the structure of meals around vegetables rather than meat (contrary to what participants with a lower vegetable consumption tend to do when mobilising competence (32)). Some competences are useful in managing specific taste issues with certain vegetables (15 and 16). The interviews were particularly important in understanding how these competences are mobilised. Most interviewees mentioned that there are several vegetables they do not find palatable. Some participants with a high or intermediate vegetable consumption thus explained they use spices to reduce or modify the taste of some vegetables they do not like, while others explained that they use sauces to enhance the flavour of some vegetables that they find too bland. In both cases, these competences enable them to eat vegetables that they would hardly eat otherwise.

\section{Discussion}

Using a training as a "test” to collect rich qualitative data on the participants' concrete practices and 
their impact on their diet addresses the main methodological challenges of the study of cooking practices, namely combining understanding and measuring (Engler-Stringer, 2010): it is more understanding-oriented than classical outcome measuring as such, and more practice-oriented than qualitative analysis. This innovative methodology does, however, share some limitations with these traditional approaches: the data were collected over a two-year period, but with a small group of participants.

Our results are consistent with other results about the barriers encountered in the preparation of raw products, which indicated the positive role of creative inspiration and the importance of proposing interventions that "highlight the importance of planning ahead and teach methods such as cooking and freezing to facilitate cooking from scratch” (McGowan et al., 2016). The competences identified in our study contribute to a more complete picture. They clarify three important points. First, they highlight the importance of "meal preparation planning” rather than what could be termed "meal eating planning" and the fact that these modes of planning have opposite effects with respect to vegetable consumption. Second, they show that essential competences had not been identified, in particular the competences that refer to prioritising quality and the competences that contribute to flexibility in preparation methods. Third, they point to the need to engage more critically with the notion of the recipe, in line with what previous studies suggested (Wolfson et al., 2017). Indeed, some studies highlighted the negative effect of time pressures on the ability to cook from scratch, the desire for effortless meals and the effect of kitchen disasters (McGowan et al., 2016). It must be noted that these three barriers are related to the very notion of the recipe. Mastering a recipe takes time; it will take even longer the first few times, and the results will be uncertain. Our results provided evidence that the participants who consumed more vegetables have developed a second strategy, namely the use of generic methods of preparation that offer a general frame, in relation to which recipes are only particular cases. This strategy reduces the learning effort and uncertainty while stimulating creative inspiration. To our knowledge, it has not been identified in previous studies on food preparation competences, although it seems to have a significant impact on the participants' diet.

Contrary to what might have been expected, the influence of food preparation competences on the diet appeared more qualitative than quantitative. Although it is true that the participants with the highest consumption of vegetables mobilise on average more competences than the participants with the lowest consumption, they mobilise less than half of the competences available (i.e. less than 23 out of 51). Indeed, a number of these competences are competing or conflicting (such as 25 and 26 or 29 and 30). Similarly, the participants with the lowest consumption of vegetables are not incompetent: they tend to pay more attention to their food budget; they generally look at pieces of 
information about the products they buy that the other participants do not consider; and they are knowledgeable enough about dishes to plan what meals they would like to eat for several days. In a nutshell, they eat what they like, keep an eye on their budget, and spend little time cooking. However, these very competences seem to be unfavourable to the consumption of vegetables. This could explain why cooking skills may not directly relate to healthy diets, a reported by several studies (Begley et al., 2017), (Fernandez et al., 2019). Our study evidences that all cooking skills do not have the same positive influence on the diet.

It must be noted that vegetables, and more specifically fresh vegetables, are a food with a number of specific features that are often underestimated in food education research when it comes to the everyday practices of home cooks. Cost, taste and ease of preparation have already been identified (Darian and Tucci, 2013). Our study provides a more complete picture: (1) seasonality affects both their availability (they may not be available at all for months from local producers) and their price (unlike that of most other products, it fluctuates, and sometimes within a couple of days); (2) their preparation tends to take more time than that of other products (because they generally need to be washed and chopped, and sometimes peeled, and their cooking time is relatively long by comparison with other raw products); and (3) the diversity of these products in most of Western Europe is high (between 20 and 30 different vegetables can be offered for sale in a market over a year), which implies a particular cognitive burden of remembering how each vegetable or group of vegetables should be chosen, stored, prepared, cooked and preserved. In order to eat fresh vegetables, home cooks must take into account all three features. This is precisely what the cluster of competences mobilised by the participants who consume the most fresh vegetables seems to do well: by choosing seasonal products, these participants adapt their purchases to the vegetables that are available under the best conditions of taste, freshness and price; they plan the time that they will devote to cooking, optimise the time they spend on each task and favour cooking double amounts in order to save time later on; and they rely on a few simple preparation outlines that they master and can then apply to many different types of vegetables.

Further studies would be needed to validate and refine these results on a larger scale, as they are based on a qualitative study of a small number of participants from one age group and in one country.

\section{Acknowledgements}

To be completed

\section{Declaration of interest statement}


The authors declare no competing interests.

\section{Table 1}

Table 1: Main Food Preparation Competences Investigated in the Study

\begin{tabular}{|c|c|}
\hline \multirow{2}{*}{$\begin{array}{l}\text { Cooking } \\
\text { techniques }\end{array}$} & 1. Prepare foods to eat them raw (e.g. in a mixed salad) \\
\hline & $\begin{array}{l}\text { 2. Steam food à l'étouffée (where the food gets cooked by the steam of its own water, with } \\
\text { very little or no added water) }\end{array}$ \\
\hline & $\begin{array}{l}\text { 3. Steam food (where the food gets cooked by the steam of water added into the pan, } \\
\text { without touching this water) }\end{array}$ \\
\hline & 4. Boil or simmer food (cooking it in a pan of hot, boiling/bubbling water) \\
\hline & 5. Stew food (cooking it for a long time in a liquid, not boiling) \\
\hline & $\begin{array}{l}\text { 6. Roast or bake food in the oven (for example raw meat/chicken, vegetables, pies, gratins, } \\
\text { etc.) }\end{array}$ \\
\hline & 7. Fry/stir-fry food in a frying pan/wok with oil or fat using the hob/gas rings/hot plates \\
\hline & 8. Microwave food (not drinks/liquids) including heating ready meals \\
\hline & 9. Grill food (cooking food directly under or above a source of direct, dry heat) \\
\hline \multirow{7}{*}{$\begin{array}{l}\text { Preparation } \\
\text { techniques }\end{array}$} & 10. Prepare flour-based dishes such as pies, using basic/raw ingredients or mixes \\
\hline & $\begin{array}{l}\text { 11. Prepare fresh vegetables (including potatoes, e.g. peel when needed, chop, slice, grate, } \\
\text { etc.) }\end{array}$ \\
\hline & 12. Prepare raw meat/poultry \\
\hline & 13. Prepare raw fish \\
\hline & 14. Prepare dried pulses (i.e. rinsing and soaking them) \\
\hline & 15. Make sauces and gravy from scratch (no ready-made jars, pastes or granules) \\
\hline & 16. Use herbs and spices to flavour dishes \\
\hline \multirow[t]{3}{*}{$\begin{array}{l}\text { Meal planning } \\
\text { and preparation }\end{array}$} & $\begin{array}{l}\text { 17. Choose the appropriate mode of food preparation and cooking to make the most of } \\
\text { available ingredients }\end{array}$ \\
\hline & 18. Plan meal preparation ahead (e.g. for the day/week ahead) \\
\hline & 19. Prepare meals in advance (e.g. packed lunch, partly preparing a meal in advance) \\
\hline
\end{tabular}




\begin{tabular}{|c|c|}
\hline & $\begin{array}{l}\text { 20. Follow specific recipes when cooking (e.g. following a particular recipe for a lamb } \\
\text { curry in mango sauce, or a butternut squash, mushroom and goat cheese pie, as described } \\
\text { in a cookbook, on a website or from someone's explanations) }\end{array}$ \\
\hline & $\begin{array}{l}\text { 21. Follow generic steps for preparing a type of dish when cooking (e.g. preparing a curry } \\
\text { or a pie based on available ingredients and generic preparation and cooking techniques for } \\
\text { this type of dish) }\end{array}$ \\
\hline & $\begin{array}{l}\text { 22. Adapt the quantity of each ingredient to obtain a specific number of servings when } \\
\text { cooking }\end{array}$ \\
\hline \multirow[t]{6}{*}{ Shopping } & $\begin{array}{l}\text { 23. Buy vegetables and fruit from suppliers other than supermarkets (e.g. market, } \\
\text { subscription, own or relatives' production) }\end{array}$ \\
\hline & 24. Go through the supermarket and purchase foods as you pass them \\
\hline & $\begin{array}{l}\text { 25. Define the meals you would like to eat first, and then go shopping with the } \\
\text { corresponding grocery list }\end{array}$ \\
\hline & $\begin{array}{l}\text { 26. Buy fresh seasonal vegetables first, and then define the meals you will prepare based } \\
\text { on these purchases }\end{array}$ \\
\hline & 27. Shop with a "refill" list \\
\hline & 28. Plan how much food to buy \\
\hline \multirow[t]{9}{*}{ Budgeting } & 29. Prioritise price when choosing between two products \\
\hline & 30. Prioritise quality when choosing between two products \\
\hline & 31. Know what budget you have to spend on food \\
\hline & $\begin{array}{l}\text { 32. Buy meat cuts that are easy to cook (best cuts such as beefsteak or processed meats } \\
\text { such as sausages or nuggets) }\end{array}$ \\
\hline & 33. Buy cheaper cuts of meat, or eggs \\
\hline & 34. Buy pulses and nuts \\
\hline & 35. Avoid buying meat \\
\hline & 36. Avoid buying snacks or sweets (including sodas) \\
\hline & $\begin{array}{l}\text { 37. Avoid buying simple ready-made foods (sandwiches, cereal mixes, etc.) and buy raw } \\
\text { ingredients instead }\end{array}$ \\
\hline \multirow[t]{3}{*}{ Resourcefulness } & 38. Cook more or double quantities, which can be used for another meal \\
\hline & 39. Improvise if needed so as to use the items available in your fridge or cupboard \\
\hline & 40. Plan the different tasks and steps so as to optimise preparation duration when cooking \\
\hline
\end{tabular}




\begin{tabular}{|c|c|}
\hline & 41. Use leftovers to create another meal \\
\hline & 42. Keep basic items in your cupboard or fridge for putting meals together \\
\hline \multirow{9}{*}{$\begin{array}{l}\text { Consumer } \\
\text { awareness }\end{array}$} & 43. Read the best-before date on food \\
\hline & 44. Prepare foods so as to use them up before they deteriorate \\
\hline & 45. Read the storage information on food packets \\
\hline & 46. Store foods so as to best preserve them \\
\hline & 47. Read the nutrition information on food labels \\
\hline & 48. Read the ingredients list on food labels \\
\hline & $\begin{array}{l}\text { 49. Balance meals based on nutrition advice (whatever the source of the advice) regarding } \\
\text { what is healthy }\end{array}$ \\
\hline & $\begin{array}{l}\text { 50. Balance meals based on food groups (vegetables, fruits, grains and starchy } \\
\text { carbohydrates, proteins, milks and alternatives) }\end{array}$ \\
\hline & $\begin{array}{l}\text { 51. Prioritise particular ethical features (e.g. local, seasonal, ethical, organic, from short } \\
\text { supply chain, etc.) }\end{array}$ \\
\hline
\end{tabular}

Table 2

Table 2: The Participants’ Vegetable Consumption Levels and Competences

\begin{tabular}{|l|l|l|l|l|l|l|l|l|l|l|l|}
\hline & \multicolumn{7}{|c|}{ Participants } \\
\hline Competences & A & B & C & D & E & F & G & H & I & J & K \\
\hline 1. Prepare foods to eat them raw & & & & & & & & & & \\
\hline 2. Steam food à l'étouffée & & & & & & & & & & & \\
\hline 3. Steam food & & & & & & & & & & & \\
\hline 4. Boil or simmer food & & & & & & & & & & & \\
\hline 5. Stew food & & & & & & & & & & & \\
\hline 6. Roast or bake food & & & & & & & & & & & \\
\hline 7. Fry/stir-fry food & & & & & & & & & & & \\
\hline 8. Microwave food & & & & & & & & & & \\
\hline
\end{tabular}




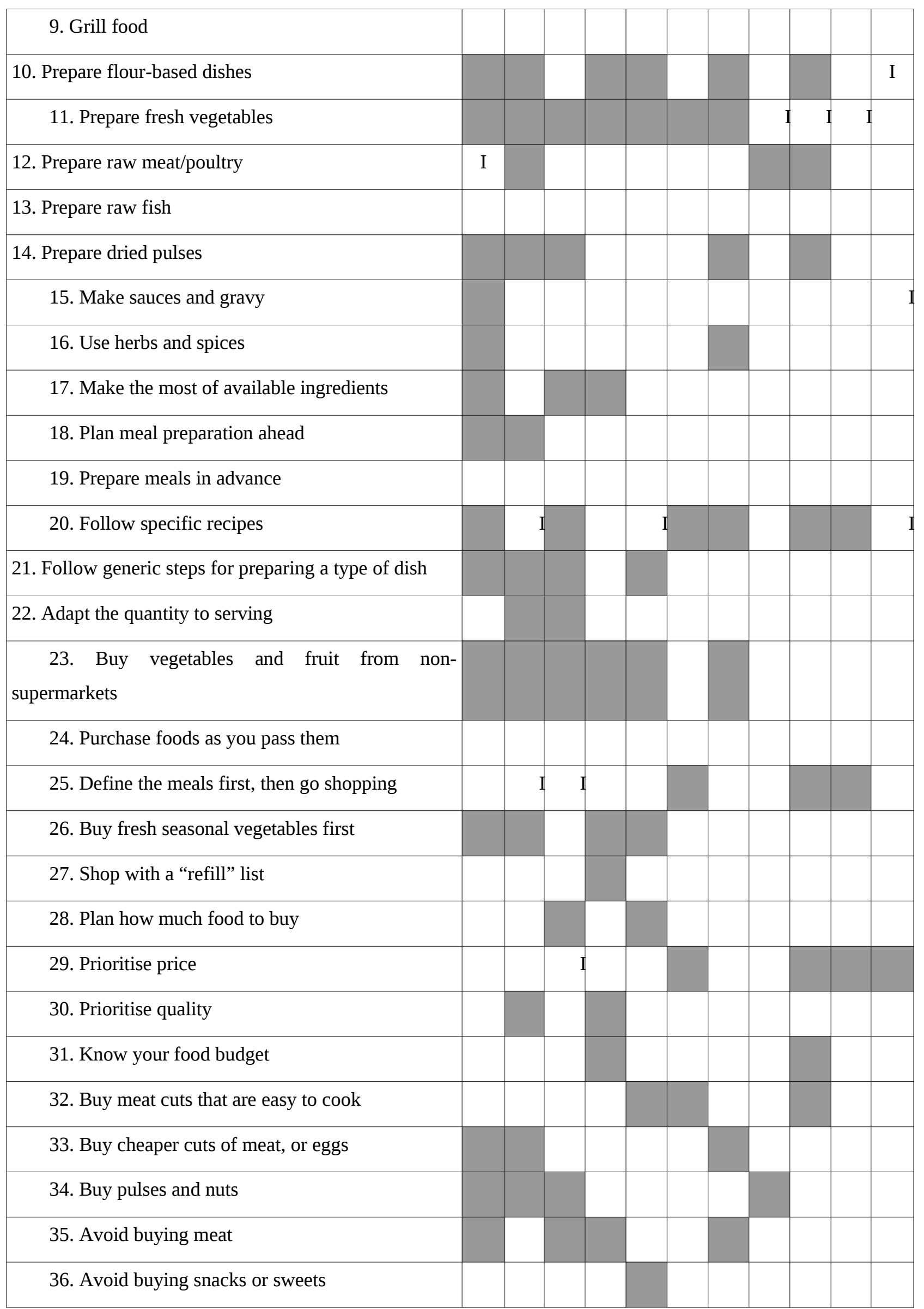




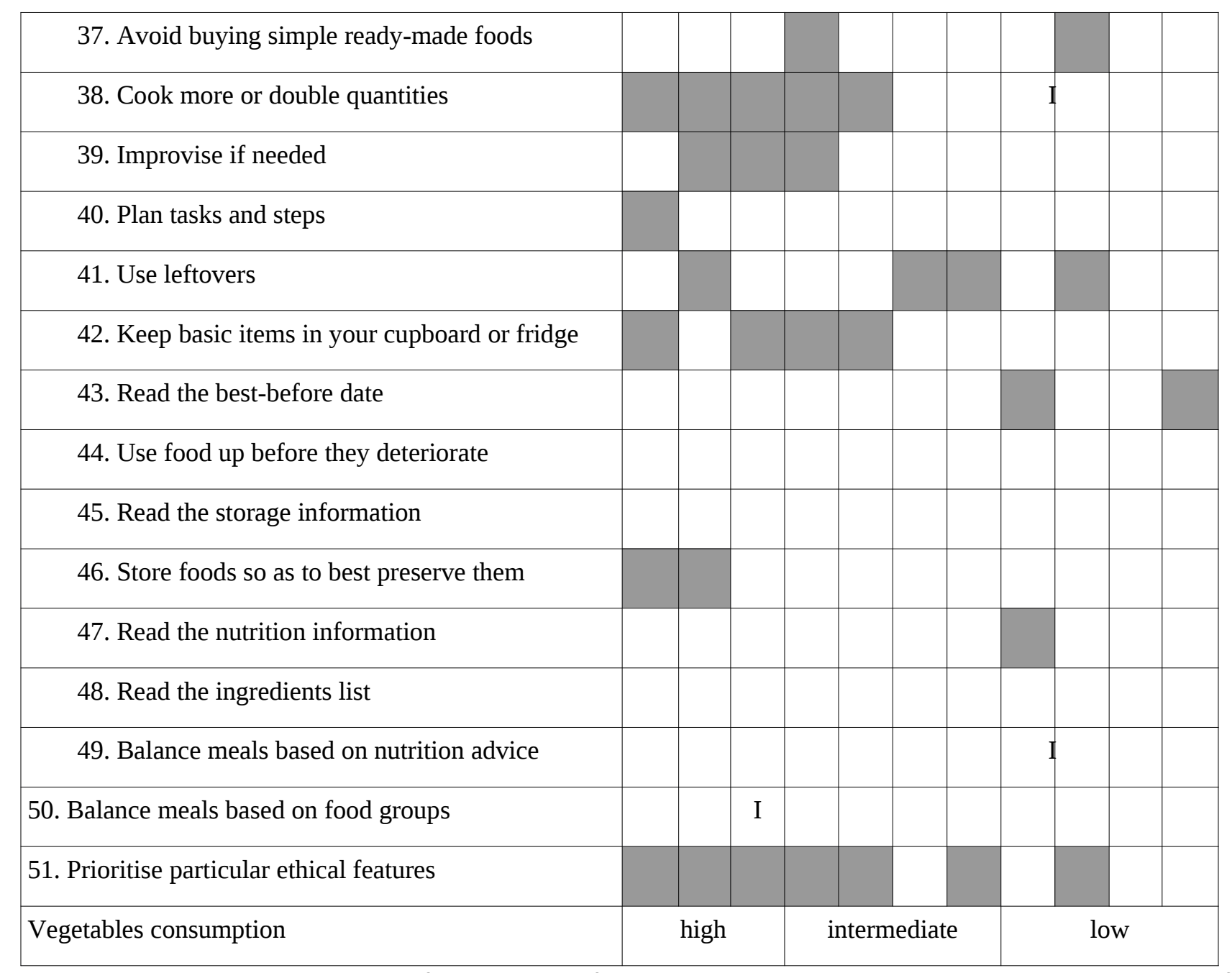

How to read: 8-10 months after the end of the training, participant B reported a high level of vegetable consumption, and reported using frequently the competences 5 (stewing), 6 (roasting or baking), 10 (preparing flour-based dishes), etc., and using infrequently the competences 20 (following specific recipes), 25 (defining meals in advance and shopping with a list) and 29 (prioritising price). 


\section{REFERENCES}

Barton, K.L., Wrieden, W.L. and Anderson, A.S. (2011), "Validity and reliability of a short questionnaire for assessing the impact of cooking skills interventions: Questionnaire assessing cooking interventions”, Journal of Human Nutrition and Dietetics, Vol. 24 No. 6, pp. 588-595.

Begley, A., Gallegos, D. and Vidgen, H. (2017), "Effectiveness of Australian cooking skill interventions”, British Food Journal, Vol. 119 No. 5, pp. 973-991.

Boltanski, L. and Thévenot, L. (2006), On Justification: Economies of Worth, Princeton University Press, Princeton.

Darian, J.C. and Tucci, L. (2013), “Developing marketing strategies to increase vegetable consumption”, Journal of Consumer Marketing, Vol. 30 No. 5, pp. 427-435.

Dinkins, J.M. (1997), "Food preparers: Their food budgeting, cost-cutting, and meal planning practices”, Family Economics \& Nutrition Review, Vol. 10 No. 2, p. 34.

Engler-Stringer, R. (2010), “Food, Cooking Skills, and Health: A Literature Review”, Canadian Journal of Dietetic Practice and Research, Vol. 71 No. 3, pp. 141-145.

Expert Consultation on Diet, Nutrition, and the Prevention of Chronic Diseases, Weltgesundheitsorganisation and FAO (Eds.). (2003), Diet, Nutrition, and the Prevention of Chronic Diseases: Report of a WHO-FAO Expert Consultation ; [Joint WHO-FAO Expert Consultation on Diet, Nutrition, and the Prevention of Chronic Diseases, 2002, Geneva, Switzerland], World Health Organization, Geneva.

Fernandez, M.A., Desroches, S., Marquis, M., Lebel, A., Turcotte, M. and Provencher, V. (2019), “Which food literacy dimensions are associated with diet quality among Canadian parents?”, British Food Journal, p. BFJ-11-2018-0724.

Fordyce-Voorham, S. (2011), “Identification of Essential Food Skills for Skill-based Healthful Eating Programs in Secondary Schools”, Journal of Nutrition Education and Behavior, Vol. 43 No. 2, pp. 116-122.

García-González, Á., Achón, M., Alonso-Aperte, E. and Varela-Moreiras, G. (2018), “Identifying Factors Related to Food Agency: Cooking Habits in the Spanish Adult Population-A CrossSectional Study”, Nutrients, Vol. 10 No. 2, p. 217. 
Garnett, T. (2014), “Changing what we eat: A call for research \& action on widespread adoption of sustainable healthy eating.”, Food Climate Research Network, University of Oxford.

Gisslevik, E. (2018), Education for Sustainable Food Consumption in Home and Consumer Studies, Acta universitatis Gothoburgensis, Göteborg.

Jomori, M.M., Vasconcelos, F. de A.G. de, Bernardo, G.L., Uggioni, P.L. and Proença, R.P. da C. (2018), “The concept of cooking skills: A review with contributions to the scientific debate”, Revista de Nutrição, Vol. 31 No. 1, pp. 119-135.

Lahne, J., Wolfson, J.A. and Trubek, A. (2017), "Development of the Cooking and Food Provisioning Action Scale (CAFPAS): A new measurement tool for individual cooking practice”, Food Quality and Preference, Vol. 62, pp. 96-105.

Larson, N., Laska, M.N., Story, M. and Neumark-Sztainer, D. (2012), "Predictors of Fruit and Vegetable Intake in Young Adulthood”, Journal of the Academy of Nutrition and Dietetics, Vol. 112 No. 8, pp. 1216-1222.

Lavelle, F., McGowan, L., Hollywood, L., Surgenor, D., McCloat, A., Mooney, E., Caraher, M., et al. (2017), "The development and validation of measures to assess cooking skills and food skills”, International Journal of Behavioral Nutrition and Physical Activity, Vol. 14 No. 1, available at:https://doi.org/10.1186/s12966-017-0575-y.

Le Boterf, G. (1994), De La Compétence, Les éditions d’organisation.

McGowan, L., Pot, G.K., Stephen, A.M., Lavelle, F., Spence, M., Raats, M., Hollywood, L., et al. (2016), “The influence of socio-demographic, psychological and knowledge-related variables alongside perceived cooking and food skills abilities in the prediction of diet quality in adults: a nationally representative cross-sectional study”, International Journal of Behavioral Nutrition and Physical Activity, Vol. 13 No. 1, available at:https://doi.org/10.1186/s12966016-0440-4.

Monroe, M.C., Plate, R.R., Oxarart, A., Bowers, A. and Chaves, W.A. (2019), "Identifying effective climate change education strategies: a systematic review of the research”, Environmental Education Research, Vol. 25 No. 6, pp. 791-812.

Notarnicola, B., Tassielli, G., Renzulli, P.A., Castellani, V. and Sala, S. (2017), “Environmental impacts of food consumption in Europe”, Journal of Cleaner Production, Vol. 140, pp. $753-$ 
765.

Poore, J. and Nemecek, T. (2018), “Reducing food's environmental impacts through producers and consumers”, Science, Vol. 360 No. 6392, pp. 987-992.

Schmidt Rivera, X.C., Espinoza Orias, N. and Azapagic, A. (2014), "Life cycle environmental impacts of convenience food: Comparison of ready and home-made meals”, Journal of Cleaner Production, Vol. 73, pp. 294-309.

Short, F. (2003a), “Domestic cooking practices and cooking skills: findings from an English study”, Food Service Technology, Vol. 3 No. 177-185.

Short, F. (2003b), “Domestic cooking skills - what are they?”, Journal of the HEIA, Vol. 10 No. 3, pp. 13-22.

Stead, M., Caraher, M., Wrieden, W., Longbottom, P., Valentine, K. and Anderson, A. (2004), “Confident, fearful and hopeless cooks: Findings from the development of a food-skills initiative”, British Food Journal, Vol. 106 No. 4, pp. 274-287.

Stibbe, A. (Ed.). (2009), The Handbook of Sustainability Literacy: Skills for a Changing World, Green, Totnes.

Sumner, J. (Ed.). (2016), Learning, Food, and Sustainability, Palgrave Macmillan US, New York, available at:https://doi.org/10.1057/978-1-137-53904-5.

Takeda, W., Melby, M.K. and Ishikawa, Y. (2017), “Food Education for Whom?: Perceptions of Food Education and Literacy among Dietitians and Laypeople in Urban Japan”, Food Studies: An Interdisciplinary Journal, Vol. 7 No. 4, pp. 49-66.

Wolfson, J.A., Bostic, S., Lahne, J., Morgan, C., Henley, S.C., Harvey, J. and Trubek, A. (2017), “A comprehensive approach to understanding cooking behavior: Implications for research and practice”, British Food Journal, Vol. 119 No. 5, pp. 1147-1158.

Worsley, T., Wang, W.C., Wijeratne, P., Ismail, S. and Ridley, S. (2015), “Who cooks from scratch and how do they prepare food?”, British Food Journal, Vol. 117 No. 2, pp. 664-676. 